\title{
Transport of solutes through calix[4]pyrrole-containing cellulose acetate films
}

\author{
A.J.M. Valente ${ }^{\mathrm{a}, *}$, A. Jiménez ${ }^{\mathrm{b}}$, A.C. Simões ${ }^{\text {a }}$, H.D. Burrows ${ }^{\mathrm{a}}$, \\ A.Ya. Polishchuk ${ }^{\text {c }}$, V.M.M. Lobo ${ }^{a}$ \\ ${ }^{a}$ Department of Chemistry, University of Coimbra, 3004-535 Coimbra, Portugal \\ ${ }^{\mathrm{b}}$ Department of Analytical Chemistry, Nutrition and Food Sciences, University of Alicante, P.O. Box 99, 03080 Alicante, Spain \\ "Kompamid LLC, 6 Proezd Zavoda "Serp\&Molot", Moscow 111250, Russia
}

Received 14 January 2007; received in revised form 21 March 2007; accepted 25 March 2007

Available online 5 April 2007

\begin{abstract}
Films of cellulose acetate containing different concentrations of meso-octamethyl-porphyrinogen (calix[4]pyrrole) were prepared and characterized using UV-vis and FTIR spectroscopy, DSC and SEM. Incorporation of calix[4]pyrrole into cellulose acetate leads to a decrease in the degree of hydrophilicity of the polymeric matrix. However, a slight increase in the percentage of water uptake of the polymer is found with an increase of the initial amount of calix[4]pyrrole in the composite composition. This effect can be related to the plasticizing effect that the calix[4]pyrrole provokes in the cellulose acetate. A comparative study of transport parameters of oxygen and some non-associated electrolytes (sodium, copper(II) and nickel chlorides) was carried out. The diffusion coefficients of molecular oxygen through cellulose acetate films decrease with an increase of the concentration of calix[4]pyrrole in the composite films. The transport (diffusion and permeation) of the above mentioned electrolytes through a set of composite films shows a decrease of permeability and diffusion coefficients with an increase of calix[4]pyrrole concentration. Such behaviour is typical of systems where interactions between the polymer and diffusing species occur. However, from the analysis of the distribution coefficient, it was found that those interactions are only dependent on the calix[4]pyrrole content for 2:1 electrolytes.
\end{abstract}

(c) 2007 Elsevier Ltd. All rights reserved.

Keywords: Cellulose acetate; Calix[4]pyrrole; Transport properties; Electrolytes; Oxygen

\section{Introduction}

Since 1960 [1,2], porphyrinogens have been extensively used for a variety of applications involving their properties as complexing agents, such as

\footnotetext{
${ }^{*}$ Corresponding author. Tel.: +351 239854459; fax: +351239 827703.

E-mail address: avalente@ci.uc.pt (A.J.M. Valente).
}

chelating agents for anions $[3,4]$, neutral molecules [5], host materials for inclusion crystals [6] and metal ion complexation [7]. Nevertheless, the need for the development of further applications of these macrocycles has been stressed in a recent publication entitled "Calix[4]pyrrole: An Old yet New Ion-Pair Receptor" [8].

Applications of such macrocycles in the solid state are usually achieved by attachment to a 
functionalized polymeric chain structure [9] or by incorporation in an appropriate solid matrix [10]. Cellulose acetate shows neutral properties, capacity for transparent film formation, and low cost. These features are, among others, responsible for the broad applications of this polymer in areas such as pharmacology [11], wastewater treatment [12], and liquid chromatography [13]. The development of the use of cellulose acetate for these different goals remains an interesting problem [14]. Furthermore, cellulose derivatives are frequently used as a supporting matrix of various other polymers $[15,16]$ or organic compounds [17]. Further, the increased development for biodegradable and naturally occurring materials as matrixes in many applications is important in order to reduce the use of materials from non-renewable sources. Cellulose acetate is one of the most important polymers in that area $[18,19]$.

We describe the preparation and characterization of cellulose acetate-containing calix[4]pyrrole composite films. The transport of oxygen is discussed in relation to potential applications of these composites in food packaging storage and preservation. Transport of various metal ion salts using a time-lag technique is also reported. These may have applications on wastewater treatment.

\section{Experimental}

\subsection{Synthesis of meso-octamethyl-porphyrinogen (CP)}

To a mixture of $1 \mathrm{~mL}(15 \mathrm{mmol})$ pyrrole and $5 \mathrm{~mL}$ acetone in a $100 \mathrm{~mL}$ round-bottom flask equipped with a magnetic stirrer, a condenser and a dropping funnel, 5-8 drops of $\mathrm{HCl}$ were added in rapid sequence. The colourless solution turned brown and showed a moderate effervescence that was followed by a rapid precipitation of acetonepyrrole, as a white solid. The calix[4]pyrrole was filtered, washed with $15 \mathrm{~mL}$ of cold acetone and dried at $40{ }^{\circ} \mathrm{C}$ for $1 / 2 \mathrm{~h}$ with a $70 \%$ yield [20].

\subsection{Membranes}

The polymeric films were prepared by initially dissolving cellulose acetate (CA) and calix[4]pyrrol (CP) in tetrahydrofuran (THF) and stirring for $24 \mathrm{~h}$. Composite films with $15 \%$ (w/v) CA and different concentrations of CP: B1, CP $(0 \% \mathrm{w} / \mathrm{v})$; B2, CP $1 \%(w / v) ; B 3$, CP $2 \%(w / v)$; and B4, CP $3 \%$ (w/v), were prepared. For all the homogeneous mixtures containing $\mathrm{CP}$ pale yellow solutions were obtained, while with cellulose acetate in the absence of CP the transparent solution was colourless. Films were deposited from these mixtures on flat glass supports by solvent evaporation using a Simex automatic film applicator. Specific moulds (Braive) were used to prepare membranes with a homogeneous thickness. After complete evaporation of solvent, membranes were removed from the glass support with the help of water.

\subsection{Polymer characterization}

Films were characterized by their infrared spectra using a ATI Mattson Genesis Series FTIR spectrometer. Polymer samples (ca. $5 \mu \mathrm{m}$ thickness) were cut from a film and dried at $60^{\circ} \mathrm{C}$ in vacuum during one day before recording spectra.

The morphologies of the polymer films were analysed using a Jeol/Scanning Microscope, model 5310 under low vacuum, and at $20 \mathrm{kV}$.

UV-spectra were obtained over the wavelength range 800 and $200 \mathrm{~nm}$, with a bandwidth of $1.0 \mathrm{~nm}$, using a Jasco V-530 spectrophotometer by directly inserting the polymer sample in the beam.

Differential scanning calorimetry (DSC) measurements were carried out in a modulated DSC instrument Q100 (TA Instruments, USA), equipped with a cooling unit (temperature range -180 to $725^{\circ} \mathrm{C}$ ). Calorimetric curves were obtained between $-50{ }^{\circ} \mathrm{C}$ and $220^{\circ} \mathrm{C}$ with a scanning rate of $10^{\circ} \mathrm{C} /$ min using dry nitrogen as the purge gas. Sample weights of about $2.2 \mathrm{mg}$ were used.

\subsection{Hydrophilicity degree}

Various samples of each membrane were cut, immersed in water, and left to equilibrate until the sample weight reached a constant value $M_{\text {eq }}$. Subsequently, the membranes were dried in a vacuum oven at $100{ }^{\circ} \mathrm{C}$ until constant weight, $M_{\mathrm{o}}$. The weight/weight $(\mathrm{w} / \mathrm{w})$ water concentration in the membrane, $C_{\mathrm{w}}$, was calculated from

$C_{\mathrm{w}}=\left(M_{\mathrm{eq}}-M_{\mathrm{o}}\right) / M_{\mathrm{eq}}$

All gravimetric measurements on water sorption were made to $\pm 0.1 \mathrm{mg}$ using an ADA $120 \mathrm{LE}$ balance.

Fluorescence measurements on membranes were carried out by using a Spex Fluorolog 111 spectrometer, with samples mounted in $1 \mathrm{~cm}^{2}$ quartz 
cuvettes and excitation at $337 \mathrm{~nm}$. A sample of each composite was immersed in an aqueous solution of pyrene $\left(P y, 10^{-5} \mathrm{M}\right)$ overnight, removed and then its fluorescence spectrum measured.

The diffusion coefficients of water in the different polymer membranes were measured using a previously described technique [21]. All the membranes were immersed in water $24 \mathrm{~h}$ before the beginning of an experiment in order to attain equilibrium rapidly. The water diffusion coefficients were determined using an adaptation of Fick's first law equation

$\rho_{0} \mathrm{~d} h / \mathrm{d} t=C_{\mathrm{w}} D_{\mathrm{w}}\left(s_{\mathrm{m}} / a_{\mathrm{c}}\right) l^{-1}$

where $\rho_{0}$ is the water density, $\mathrm{d} h / \mathrm{d} t$ is the variation of the height of column of water in the capillary tube with time, $C_{\mathrm{w}}$ is the weight/weight water concentration in the membrane surface in contact with water phase calculated according to Eq. (1), $s_{\mathrm{m}}$ is the area of membrane surface, and $a_{\mathrm{c}}$ is the capillary area.

\subsection{Oxygen permeation}

Oxygen permeation through the polymer films was measured using a Permeation Analyser Systech Instruments-Model 8500. All experiments were carried out at a pressure of $2.5 \mathrm{~atm}$. The amount of oxygen which permeated per unit of time was continuously monitored until a steadystate was reached. Thickness of films was measured at $25^{\circ} \mathrm{C}$ using a Mitutoyto micrometer $( \pm 0.01 \mathrm{~mm})$.

The amount of oxygen that permeates a thin sheet, $F$, may be obtained from the general diffusion

$F=-D \operatorname{grad} C$

When the diffusion coefficient, $D$, is independent of concentration, $C$, the one-dimensional solution of Eq. (3) can be expressed as Eq. (4) which describes the above mentioned process with boundary conditions according to Fick's second law equation [22] for a film sheet tested by an isostatic permeation experiment [23]

$\frac{F_{\mathrm{t}}}{F_{\infty}}=\frac{2 l}{\sqrt{\pi D t}} \sum_{n=1,3,5, \ldots}^{\infty} \exp \left(\frac{-n^{2} l^{2}}{4 D t}\right)$

where $F_{\mathrm{t}}$ is the flow rate of oxygen permeating the film at the transient state at time $t, F_{\infty}$ is the oxygen transmission rate at the steady state, $l$ is the film thickness, and $D$ is the oxygen diffusion coefficient.

Using the value of permeant flow at steady-state $F_{\infty}$, the permeability coefficient $P$ is determined by Eq. (5)

$P=\frac{F_{\infty} l}{A \Delta p}$

where $A$ is the area of the film, and $\Delta p$ is the partial pressure gradient across the polymer film. Maintaining $(A \Delta p)$ constant throughout all experiments, $P$ is proportional to the permeant flux, $Q\left(=F_{\infty} l\right)$.

\subsection{Permeation experiments}

Permeability of electrolytes was measured using a previously reported device [12]. This consists of two $250 \mathrm{~mL}$ compartments filled with surfactant solution (A) and water (B), respectively, with the polymer membrane sealed, with silicone, between these two tubes. The change in the ionic solute concentration in cell B was determined during the permeability experiment by different methods depending on electrolytes. In the case of $\mathrm{NaCl}$ (Aldrich, pro-analysis), the flux was quantified by measuring the electrical conductivity using a YSI 3200 instrument. This was calibrated prior to each experiment using at least five freshly prepared standard solutions of the electrolyte, with different concentrations. The same conditions were used for calibration and permeability experiments. Constant temperature $\left( \pm 0.1^{\circ} \mathrm{C}\right)$ was maintained by immersing the system in a thermostat bath (Velp Sientifica Multistirrer 6). Solutions in both compartments were stirred at ca. $200 \mathrm{rpm}$.

In the case of $\mathrm{CuCl}_{2} \cdot 2 \mathrm{H}_{2} \mathrm{O}$ (Aldrich, $>98 \%$ ) and $\mathrm{NiCl}_{2}(\mathrm{M} \& \mathrm{~B},>98 \%)$, the conductivity measurements were accompanied by measurements of the concentration of cations that cross the membrane, using HI95747 and HI93740 photometers (Hanna Instruments), respectively, in order to check how cation hydrolysis [24] can affect the behaviour. The detection limit for these measurements are 23.6 and $17.0 \mathrm{mM}$ for $\mathrm{Cu}(\mathrm{II})$ and $\mathrm{Ni}(\mathrm{II})$, respectively. It was found that, in the studied concentration range, both results of transport of $\mathrm{Cu}(\mathrm{II})$ and $\mathrm{Ni}(\mathrm{II})$ are in agreement.

The permeability of ionic solutes through the polymeric membranes can be described in terms of Fickian diffusion

$\partial C / \partial t=\partial / \partial X\left(D_{\mathrm{F}} \partial C / \partial X\right)$ 
with the boundary and initial conditions $C(0, t)=C$; $C(l, t)=0$, (where $C$ is the ionic concentration inside the membrane) and $C(x, 0)=0$, resulting in the simple formulae for calculation of the permeability, $P$, and diffusion, $D_{\mathrm{F}}$, coefficients

$P=J l / c$

$D_{\mathrm{F}}=l^{2} /(6 \theta)$

where $J$ is a steady-state flux through the membrane, $\theta$ is the time-lag, and $c$ is the bulk electrolyte concentration. $l$ is measured after each experiment at $25^{\circ} \mathrm{C}$ using a Mitutoyto micrometer $( \pm 0.001 \mathrm{~mm})$.

\section{Results and discussion}

\subsection{Film characterization}

The incorporation of calix[4]pyrrole $(\mathrm{CP})$ in a cellulose acetate (CA) matrix produced a clear and a macroscopic homogeneous film, indicating that no apparent phase separation had occurred between polymer and macrocyle during the composite film formation. Fig. 1 shows the effect of $\mathrm{CP}$ on the UV-visible spectra of the composite films. The presence of $\mathrm{CP}$ in the $\mathrm{CA}$ films is responsible for a relatively broad absorption peak at $278 \mathrm{~nm}$ (Fig. 1). Although other CP-based transitions, together with light scattering may be responsible for the increasing absorbance at shorter wavelengths, we believe that this peak does allow quantification of the $\mathrm{CP}$ in the film. In agreement with this, the absorbance of this increased linearly with macrocycle concentration, following the Beer-Lambert law. Although the absorbance values are at the limits of application of the Beer-Lambert relation, these values suggest that $\mathrm{CP}$ is physically incorporated as isolated molecules inside CA matrix. This is in agreement with observations from FTIR.

Fig. 2 shows, as example, the infrared spectra of B1 and B4 films. In addition to the characteristic cellulose acetate bands at 1748, 1234 and $1046 \mathrm{~cm}^{-1}$ [25], new bands are observed at 1578 $\left(\mathrm{C}=\mathrm{C}_{\text {aromatic }}\right), \quad 2887 \quad\left(\mathrm{C}-\mathrm{H}_{\text {aliphatic }}\right)$ and 3440 $(\mathrm{N}-\mathrm{H}) \mathrm{cm}^{-1}$. These bands are indicative of the $\mathrm{CP}$ incorporation to cellulose acetate matrix. However, no changes in the bands (collapse, shift) are found in the presence and absence of $\mathrm{CP}$, suggesting that physical incorporation of $\mathrm{CP}$ occurs.

In this context, the glass transition temperature $\left(T_{\mathrm{g}}\right)$ of CA films decreased about $30^{\circ} \mathrm{C}$ (from $190{ }^{\circ} \mathrm{C}$ to $\mathrm{B} 1$ to $159^{\circ} \mathrm{C}$ to $\left.\mathrm{B} 4\right)$ as $\mathrm{CP}$ concentration increased from $0 \%$ to $3 \%$ (Fig. 3), suggesting that the incorporated macrocycle acts as a plasticizer and increases the mobility of the polymer molecules. It is also worthy of note that the endo-

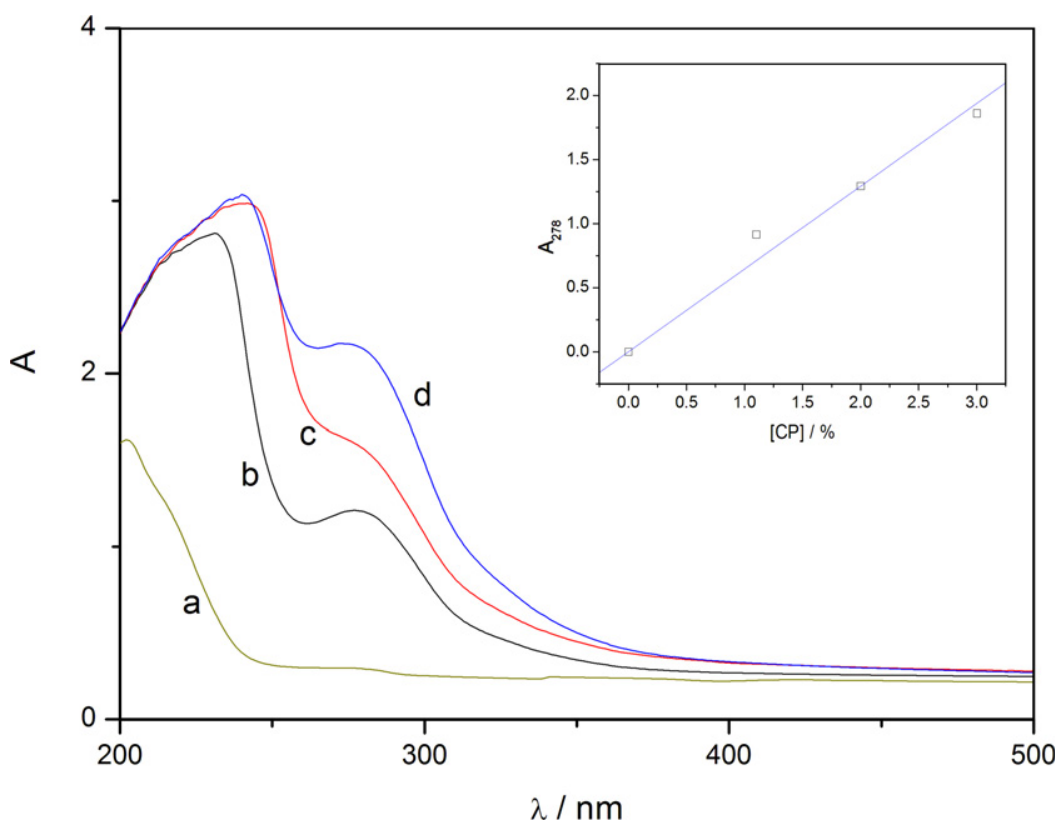

Fig. 1. UV-visible spectra of cellulose acetate films (see Section 2.2). (a) B1; (b) B2; (c) B3; (d) B4. Inset: Beer-Lambert plot of absorption at $278 \mathrm{~nm}$ as a function of calix[4]pyrrole. 


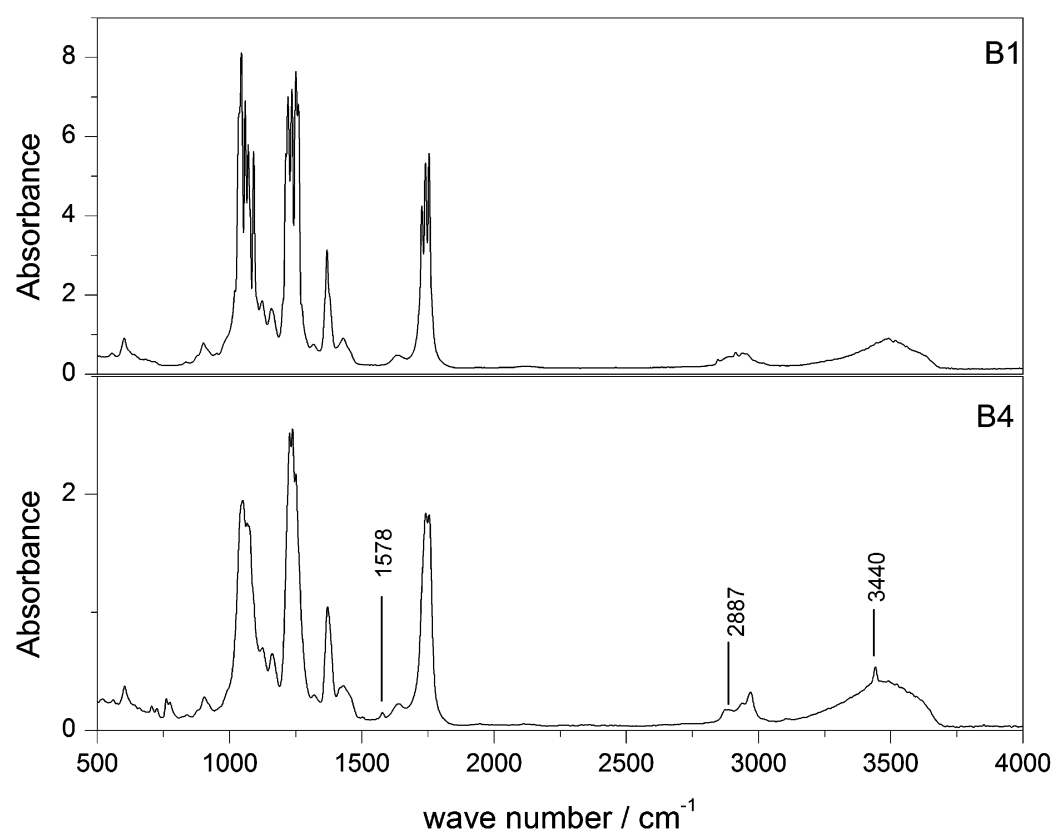

Fig. 2. Infrared spectra of cellulose acetate (B1) and cellulose acetate-calix[4]pyrrole (B4) films.

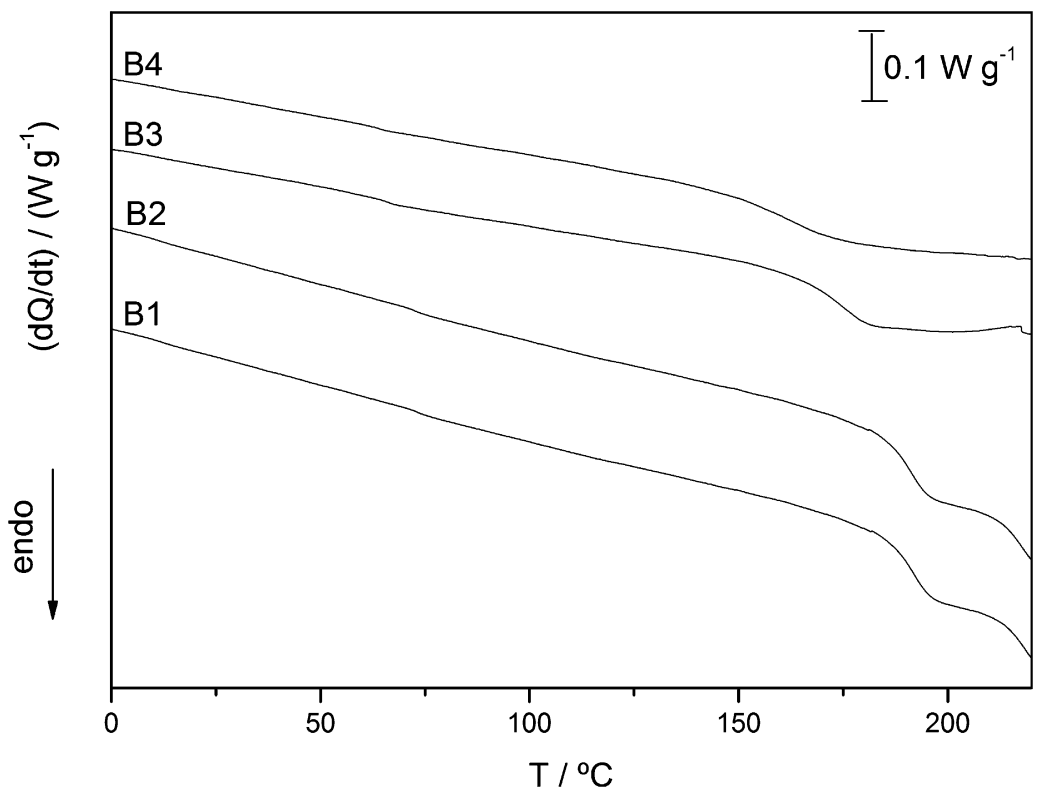

Fig. 3. DSC curves for heating runs performed on cellulose acetate-calix[4]pyrrole films at $10^{\circ} \mathrm{C} / \mathrm{min}$.

thermic transition decreased as the $\mathrm{CP}$ concentration decreased, showing that the macrocycle decreased the crystallinity of the cellulose acetate matrix.

The effect of CP on the morphology of CA films surface was analyzed by SEM. Fig. 4 shows the effects of $\mathrm{CP}$ incorporation on the surface structure/morphology.

In the CA film, the degree of porosity was very high and relatively homogeneous throughout the analyzed surface. The pore sizes were quite heterogeneous, with the larger ones reaching a diameter of $1.6 \mu \mathrm{m}$. With CP incorporation, the surface of 
a

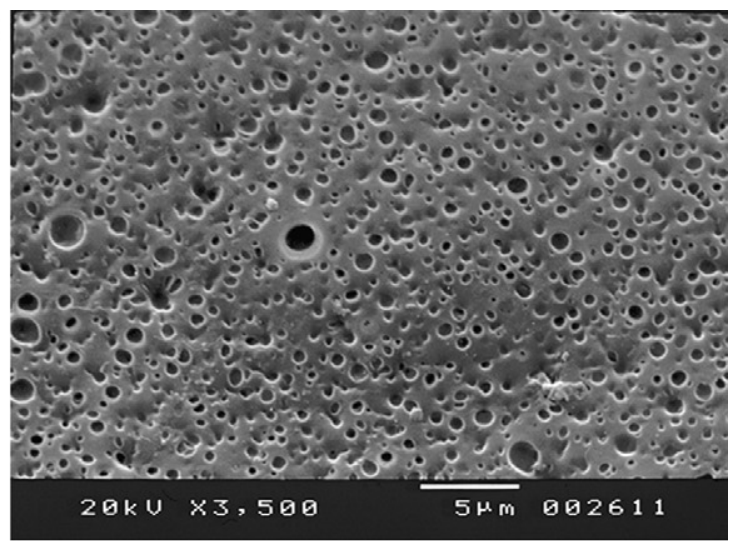

b

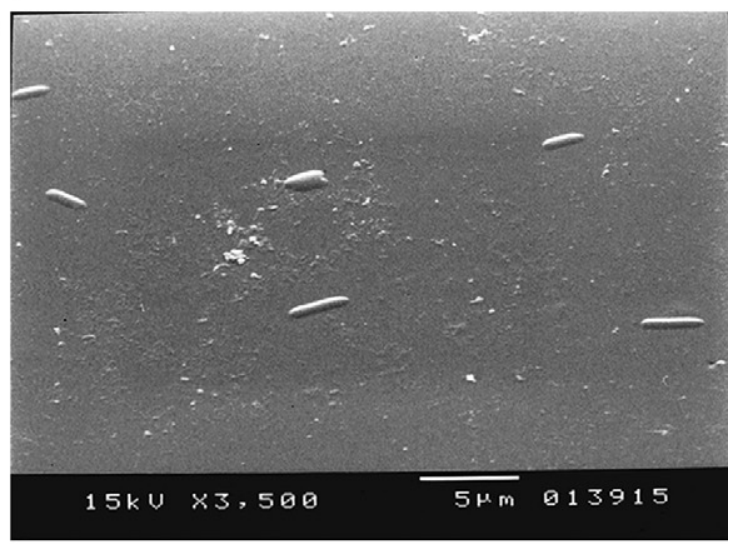

C

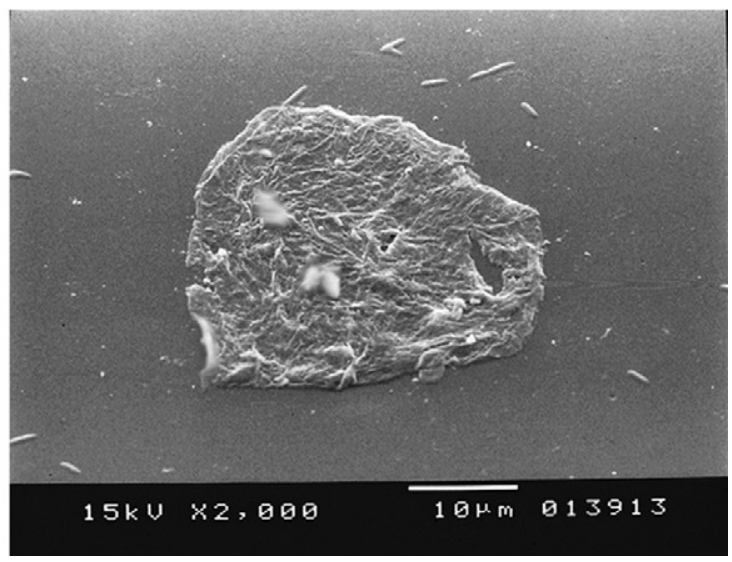

Fig. 4. SEM micrographs of (a) cellulose acetate, (b) B2 and (c) B4 films.

polymeric films changed, suggesting a fairly compact surface morphology. There were indications of phase separation, as can be seen by the formation of some microscopic heterogeneities in the form of surface crystallites (Fig. 4b). Further evidence of phase separation due to macrocycle incorporation [9] is seen in Fig. 4c, where a large structure of around $30 \mu \mathrm{m}$ can be observed.
Support for surface morphology alteration accompanied by an increase in hydrophobicity upon $\mathrm{CP}$ concentration comes from fluorescence studies on the polymeric films using pyrene $(\mathrm{Py})$ as a probe. Relative intensities, $I_{1} / I_{3}$, of the first and third vibronic bands of Py fluorescence, which are a measure of local polarity [26], were measured for the systems $\mathrm{Py} / \mathrm{CP}$ in solution and $\mathrm{Py} / \mathrm{CA}-\mathrm{CP}$ using an integrating sphere. Relative intensities $\left(I_{1} / I_{3}\right)$ of Py $(1 \mu \mathrm{M})$ for solutions of $\mathrm{CP}$ of concentrations $0.01,0.02$ and $0.03 \mathrm{mM}$ are $1.39,1.33$ and 1.31 , respectively, suggesting that the polarity of solutions decrease as $[\mathrm{CP}]$ increases. Studies of $I_{1} / I_{3}$ of Py $(1 \mu \mathrm{M})$ in CA-CP films show a similar decrease of the relative intensities with an increase of $\mathrm{CP}$ concentration (values for films are: $\mathrm{B} 1: I_{1} / I_{3}=1.60 ; \mathrm{B} 2: I_{1} / I_{3}=$ 1.59; B3: $I_{1} / I_{3}=1.48$; and B4: $I_{1} / I_{3}=1.37$ ), showing that the polarity of the films decreases, and hence hydrophobicity increases, on incorporation of the macrocycle.

This increase in hydrophobicity is also seen in the decrease in the percentage of water uptake of the different polymeric films, which goes from $0.7 \mathrm{~g} / \mathrm{g}$, in cellulose acetate, to ca. $0.1 \mathrm{~g} / \mathrm{g}$ in composite (B2-B4) films (Table 1). It is interesting to note that although the percentage of water uptake clearly decreases when CP is incorporated, a linear relationship (with a very low slope) between $C_{\mathrm{w}}$ and $\mathrm{CP}$ concentration is found. Simultaneously, a continuous decrease of water diffusion coefficients is observed from $8 \times 10^{-12} \mathrm{~m}^{2} \mathrm{~s}^{-1}$ in $\mathrm{B} 1$ to around $1 \times 10^{-12} \mathrm{~m}^{2} \mathrm{~s}^{-1}$ to B4 (Table 1). The experimental results can be explained according to the cluster model for water diffusion. This model is based on the reasonable suggestion that interaction between water molecules exceeds polymer-water interactions [27]. The presence of the calix[4]pyrrole may be the contributing factor to water association, since it is known that pyrrole nitrogens can generate a cone conformation and, consequently, hydrogen bonding can occur between water molecules and pyrrole NH groups [28]. The DSC analysis is in agreement with

Table 1

Concentration, $C_{\mathrm{w}}$, and diffusion coefficients, $D_{\mathrm{w}}$, of water in calyx[4]pyrrole-containing cellulose acetate composite films

\begin{tabular}{lll}
\hline Polymer & $C_{\mathrm{w}}(\mathrm{g} \mathrm{g})$ & $D_{\mathrm{w}}\left(10^{-12} \mathrm{~m}^{2} \mathrm{~s}^{-1}\right)$ \\
\hline B1 & $0.70( \pm 0.06)$ & $8.31( \pm 0.15)$ \\
B2 & $0.11( \pm 0.01)$ & $2.96( \pm 0.06)$ \\
B3 & $0.15( \pm 0.01)$ & $1.27( \pm 0.08)$ \\
B4 & $0.16( \pm 0.03)$ & $1.17( \pm 0.06)$ \\
\hline
\end{tabular}


this model, since it is expected that $T_{\mathrm{g}}$ will shift towards lower temperatures as the water content increases; it was also observed that the contribution for heat sorption tends to decrease with an increase of water-water interactions [29]. As indicated before, clustering is likely to produce significant immobilization of water molecules and, consequently, a decrease in the effective diffusion coefficients with an increase in the total concentration of diffusant (water molecules, in this case), in close agreement with our data.

\subsection{Transport properties}

\subsubsection{Permeation of oxygen}

Fig. 5 shows the kinetics of $\mathrm{O}_{2}$ transport through films B1-B4. Three different conclusions may be obtained from these data. (a) the experimental data fit reasonable well to Eq. (4); (b) the steady-state $\mathrm{O}_{2}$ flux is reached slowly when $\mathrm{CP}$ concentration increases; and (c) at long time-scales (when $F_{\mathrm{t}} / F_{\infty}$ approaches 1 - Fig. 5: inset) a negative deviation of experimental results, compared to the fitting line, is indicative of some retarding effect on diffusion; i.e, such a deviation may indicate some association between $\mathrm{O}_{2}$ and the polymeric film. The values of the diffusion coefficient $(D)$, obtained by fitting Eq. (4) to experimental data using Origin software, a nonlinear least-squares method $(95 \%$ confidence limits), and the flux $(Q)$ of oxygen through different composite films are shown in Table 2. The diffusion coefficient of $\mathrm{O}_{2}$ in cellulose acetate membranes obtained in this work $\left(1.33 \times 10^{-12} \mathrm{~m}^{2} \mathrm{~s}^{-1}\right)$ is similar to that reported elsewhere $\left(1.8-1.9 \times 10^{-12} \mathrm{~m}^{2} \mathrm{~s}^{-1}\right)$ [30] using cellulose acetate with higher molecular weight $(61,000 \mathrm{Da})$ membranes. The presence of calix[4]pyrrole into the cellulose ester matrix leads to a decrease in the flux of $\mathrm{O}_{2}$; however, there is no effect of $Q$ on the $\mathrm{CP}$ concentration. These results show that alterations provoked by incorporation on the hydrophobicity and on the surface morphology of composites act as the main obstacles to $\mathrm{O}_{2}$ permeation. When diffusion coefficients are analysed, there is a continuous slight decrease of $D$ with increasing CP fraction in the cellulose acetate matrix. Although DSC results suggest that CP can act as plasticizer in the composite, the free space for $\mathrm{O}_{2}$ diffusion decreases with an increase of $\mathrm{CP}$; such behaviour can be justified by association of $\mathrm{O}_{2}$ with calix[4]pyrrole decreasing the polymer free volume available for $\mathrm{O}_{2}$ transport.

\subsubsection{Permeation of electrolytes}

Permeability experiments were carried out with the chlorides of sodium, nickel (II) and copper (II). A common anion was used because the nature of the counterion has an effect on transport behaviour [31]. The last two electrolytes are quite commonly

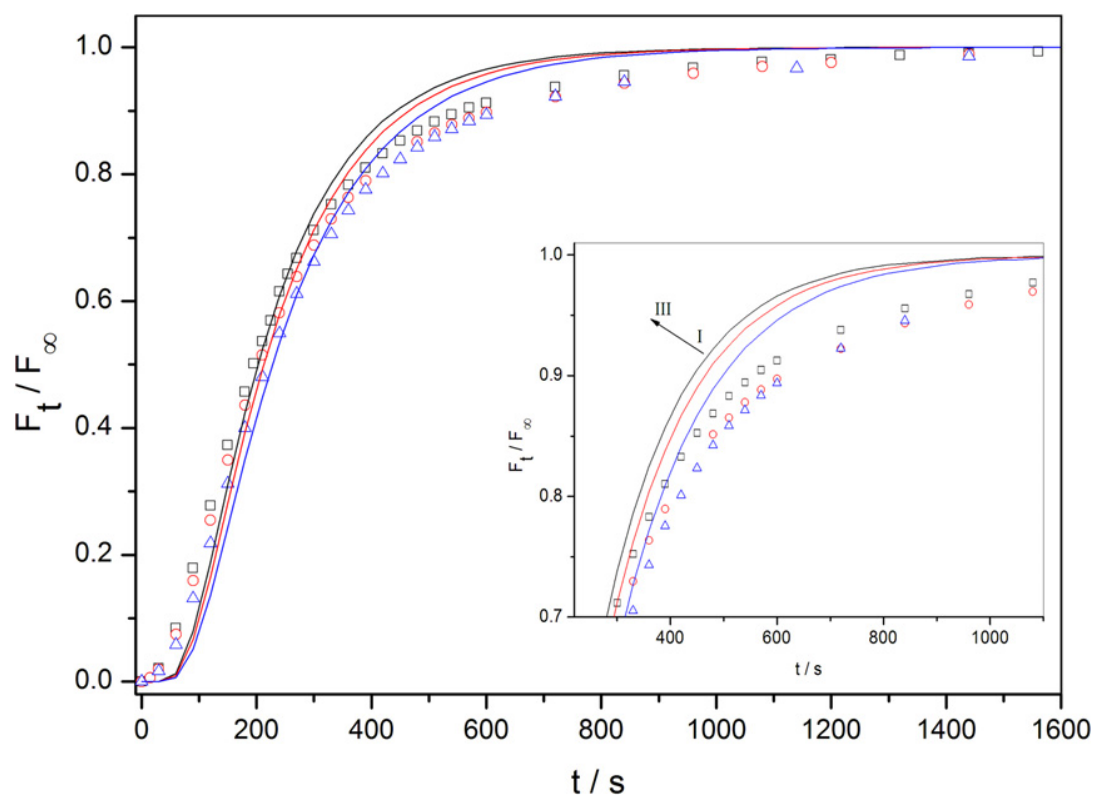

Fig. 5. Transport kinetics of $\mathrm{O}_{2}$ through: $(\square) \mathrm{B} 1,(\mathrm{O}) \mathrm{B} 2$ and $(\triangle) \mathrm{B} 4$. Solid lines represent $F_{\mathrm{t}} / F_{\infty}$ predicted by Eq. (4): (I) B1, (II) B2 and (III) B4. For the sake of simplicity, experimental data of flux of $\mathrm{O}_{2}$ through B3 was not plotted. 
Table 2

Transport properties $(Q$ and $D)$ of oxygen through cellulose acetate-calix[4]pyrrole films of $40 \mu \mathrm{m}$ thickness

\begin{tabular}{lll}
\hline Polymer & $Q /\left(10^{-2} \mathrm{~cm}^{3} \mathrm{O}_{2} \mathrm{~m}^{-1} \mathrm{day}^{-1}\right)$ & $D /\left(10^{-12} \mathrm{~m}^{2} \mathrm{~s}^{-1}\right)$ \\
\hline B1 & $10.9( \pm 0.9)$ & $1.33( \pm 0.03)$ \\
B2 & $8.07( \pm 0.9)$ & $1.26( \pm 0.03)$ \\
B3 & $7.99( \pm 0.3)$ & $1.24( \pm 0.02)$ \\
B4 & $7.54( \pm 0.8)$ & $1.18( \pm 0.02)$ \\
\hline
\end{tabular}

identified in industrial wastewaters and in environmental residuals. We are therefore interested in checking the effect of calix[4]pyrrole/cellulose acetate composites in relation to potential removal of such ions from solution; $\mathrm{NaCl}$ was chosen as a "reference" electrolyte. The permeability coefficients for the above salts (Table 3) are dependent on the calix[4]pyrrole incorporation and on the type of salt. $P$ decreases with an increase of calix[4]pyrrole concentration in the composite, and for each composite, $P$ changes according to: $P(\mathrm{NaCl})>P\left(\mathrm{NiCl}_{2}\right)>$ $P\left(\mathrm{CuCl}_{2}\right)$, suggesting that the flux may either be dictated by the hydrated radius of cation $\left(r_{\mathrm{H}}\left(\mathrm{Cu}^{2+}\right)=\right.$ $\left.4.19 \AA>r_{\mathrm{H}}\left(\mathrm{Ni}^{2+}\right)=4.04 \AA>r_{\mathrm{H}}\left(\mathrm{Na}^{+}\right)=3.58 \AA\right)$ [32] or by binding of the cation to the CP, which is expected to follow the order $K\left(\mathrm{Cu}^{2+}\right)>K\left(\mathrm{Ni}^{2+}\right)>$ $K\left(\mathrm{Na}^{+}\right)$[33]. In addition the permeability coefficients decrease with an increase of $\mathrm{CP}$ concentration in the membrane. Such behaviour is more evident with membranes B1 and B2, suggesting that an important factor affecting permeation may be the degree of hydration of the polymer. However, when comparing membranes with higher concentrations of $\mathrm{CP}$ (B2-B4), the degree of hydration of the membrane is no longer the dominant factor responsible for such a change in $P$; in this case, alterations in the polymer morphology as well as interactions between electrolytes and $\mathrm{CP}$, with the consequent reduction of the free volume available for permeation, may be involved.

Generally, with steady-state transport processes through membranes, there is a time-lag $(\theta)$ associated with the dissolution of the permeant species to a constant level before the steady state is achieved. In addition, an increase in the induction period may be found with an increase in the interaction between the permeant species and the polymeric matrix [34]. It is clear from data shown in Table 3 that not only is the time-lag extended by the presence of increasing amounts of calix[4]pyrrole but the final steady-state permeation is also affected. Both phenomena are significant and clearly suggest a transport mechanism involving interactions between electrolytes and the polymer, with the major effect depending upon CP. Quantification of the amount of electrolyte retained by the polymeric matrix can be calculated by the distribution coefficients, $K,\left(K=P / D_{\mathrm{F}}\right)$. From the analysis of $K$ values, it is possible to conclude that, although there is a clear effect of the macrocycle on the transport of the different electrolytes, the equilibrium behaviour of $\mathrm{NaCl}$ is unperturbed by the presence of calix[4]pyrrole. However, it is found that the amount of $\mathrm{Cu}$ (II) and $\mathrm{Ni}(\mathrm{II})$ sorbed by the matrix increase with the increase of $\mathrm{CP}$ concentration.

A further point deserving discussion concerns the values of the diffusion coefficients of these elec-

Table 3

Transport properties of $\mathrm{NaCl}, \mathrm{NiCl}_{2}$, and $\mathrm{CuCl}_{2}$ through calix[4]pyrrole-containing cellulose acetate composite films

\begin{tabular}{|c|c|c|c|c|}
\hline Composite & $P\left(10^{-13} \mathrm{~m}^{2} \mathrm{~s}^{-1}\right)$ & $\theta(\mathrm{s})$ & $D\left(10^{-13} \mathrm{~m}^{2} \mathrm{~s}^{-1}\right)$ & $K$ \\
\hline & $\mathrm{NaCl}$ & & & \\
\hline $\mathrm{B} 1$ & $14.2( \pm 0.02)$ & $3470( \pm 98)$ & $3.89( \pm 0.1)$ & $3.7( \pm 0.1)$ \\
\hline B2 & $12.6( \pm 0.04)$ & $4753( \pm 67)$ & $2.84( \pm 0.04)$ & $4.4( \pm 0.1)$ \\
\hline B3 & $9.86( \pm 0.03)$ & $5870( \pm 287)$ & $2.30( \pm 0.11)$ & $4.3( \pm 0.2)$ \\
\hline B4 & $8.76( \pm 0.06)$ & $6081( \pm 167)$ & $2.22( \pm 0.06)$ & $3.9( \pm 0.1)$ \\
\hline & $\mathrm{NiCl}_{2}$ & & & \\
\hline B1 & $13.0( \pm 0.10)$ & $5510( \pm 287)$ & $2.35( \pm 0.12)$ & $5.5( \pm 0.3)$ \\
\hline $\mathrm{B} 2$ & $8.77( \pm 0.06)$ & $16,585( \pm 453)$ & $0.81( \pm 0.02)$ & $10.8( \pm 0.3)$ \\
\hline B3 & $6.56( \pm 0.02)$ & $24,456( \pm 579)$ & $0.55( \pm 0.01)$ & $11.9( \pm 0.3)$ \\
\hline B4 & $5.74( \pm 0.01)$ & $32,609( \pm 981)$ & $0.41( \pm 0.01)$ & $13.9( \pm 0.4)$ \\
\hline & $\mathrm{CuCl}_{2}$ & & & \\
\hline B1 & $11.0( \pm 0.06)$ & $6818( \pm 456)$ & $1.98( \pm 0.13)$ & $5.6( \pm 0.4)$ \\
\hline B2 & $7.95( \pm 0.04)$ & $18,776( \pm 1103)$ & $0.72( \pm 0.04)$ & $11.1( \pm 0.7)$ \\
\hline B3 & $5.95( \pm 0.01)$ & $28,970( \pm 980)$ & $0.47( \pm 0.02)$ & $12.8( \pm 0.4)$ \\
\hline B4 & $4.89( \pm 0.02)$ & $40,786( \pm 2504)$ & $0.33( \pm 0.02)$ & $14.8( \pm 0.9)$ \\
\hline
\end{tabular}


trolytes in the polymer membranes. The diffusion coefficient of $\mathrm{NaCl}$ in unmodified cellulose acetate is similar to that reported elsewhere [21]. For the $\mathrm{CP}$-containing membranes, the diffusion coefficients, $D_{\mathrm{F}}$, of the salts for each composite decrease in the same tendency: $\mathrm{NaCl}>\mathrm{NiCl}_{2}>\mathrm{CuCl}_{2}$. This is the same order of the diffusion coefficients of the above salts in aqueous solutions, showing that diffusion of the free diffusing species through the polymeric matrix acts as in water; in fact, a linear relationship between the logarithm of $D_{\mathrm{F}}$, normalised to the diffusion coefficients of the respective salts in aqueous solutions, $D_{0}$, and the square root of the hydrated cation radius, $r_{\mathrm{H}}$, is found (Fig. 6). The effect of $r_{\mathrm{H}}$ on the diffusion coefficient becomes more important when the amount of $\mathrm{CP}$ increases. The decrease of $D_{\mathrm{F}}$ with an increase of $r_{\mathrm{H}}$ and CP can be explained by an increase in the coefficient to resistance, which is a measure of the friction acting on a solute as it moves through a solvent [35], and/ or by a decrease in the effective free volume. Both phenomena may occur in our systems. That is, the friction acting in a larger ion is greater than in a corresponding smaller ion and, consequently, the diffusion process is less effective; at the same time, the presence of $\mathrm{CP}$, with a consequent interaction with electrolytes, provokes a clear decrease in the free volume with a corresponding decrease of $D$.

\section{Conclusions}

The incorporation of $\mathrm{CP}$ in cellulose acetate matrices was described. The characterization of those composites shows that no chemical reactions occur between CP and CA. The physical-chemical properties of the composite films depend on the balance of different factors, such as an increase of hydrophobicity of the polymeric bulk structure due to the presence of calix[4]pyrrole; the plasticizing effect of CP and alterations of the surface morphology. The presence of calix[4]pyrrole also provokes the formation of water clusters which explain the decreasing of effective water diffusion coefficients with the increasing of water sorption.

The increasing amount of calix[4]pyrrole in composite films led to a decrease in the diffusion coefficients of $\mathrm{O}_{2}$, which can be explained by the possible complexation calix[4]pyrrole- $\mathrm{O}_{2}$ or by an increase of the "free volume" for $\mathrm{O}_{2}$ entrapment. However, in all cases the kinetics of diffusion shows a small deviation to the Fick's second law equation.

The diffusion and permeability coefficients of $0.1 \mathrm{M}$ solutions of $\mathrm{NaCl}, \mathrm{CuCl}_{2}$ and $\mathrm{NiCl}_{2}$ decrease

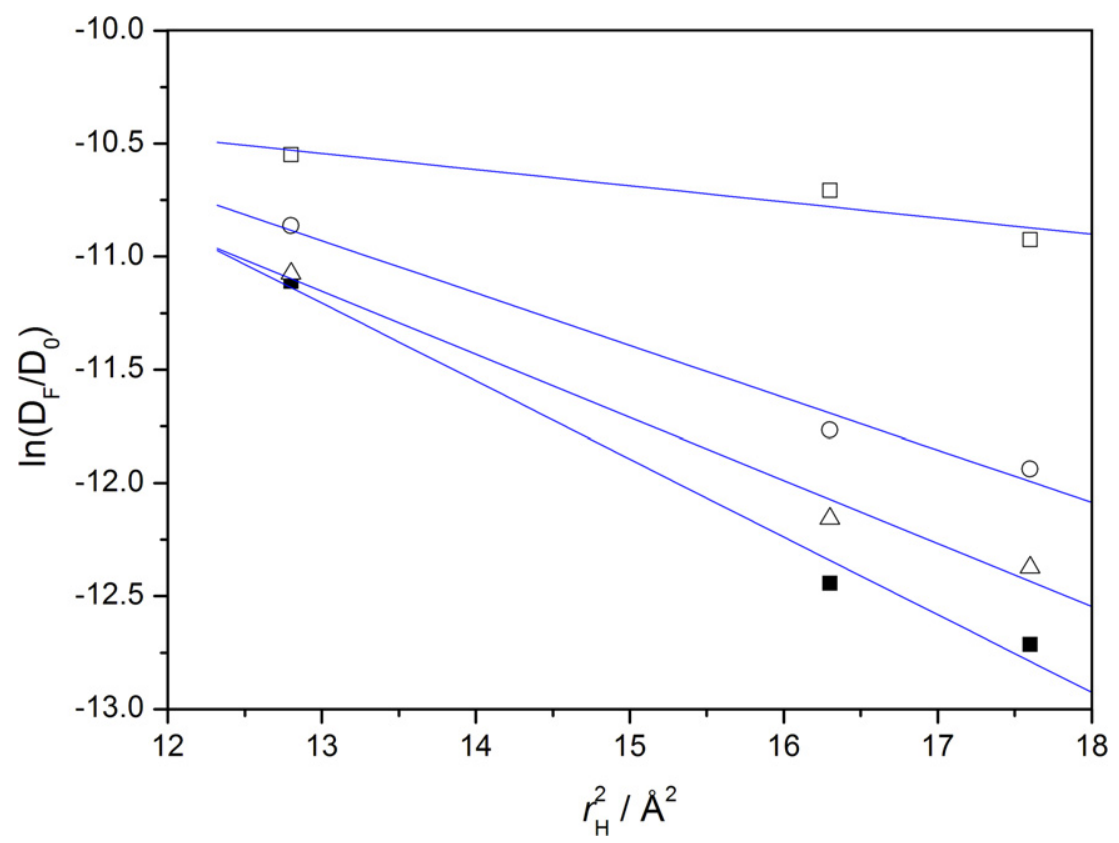

Fig. 6. Effect of hydrated cation radius, $r_{\mathrm{H}}$, on the logarithm of diffusion coefficients of electrolytes in the different cellulose acetate-based composites: $(\square) \mathrm{B} 1,(\bigcirc) \mathrm{B} 2,(\triangle) \mathrm{B} 3$, and $(\boldsymbol{\square}) \mathrm{B} 4 . D^{0}(\mathrm{NaCl}, 0.1 \mathrm{M})=1.843 \times 10^{-9} \mathrm{~m}^{2} \mathrm{~s}^{-1}[36], D^{0}\left(\mathrm{NiCl}_{2}, 0.1 \mathrm{M}\right)=1.050 \times 10^{-9} \mathrm{~m}^{2} \mathrm{~s}^{-1}[36]$, $D^{0}\left(\mathrm{CuCl}_{2}, 0.05 \mathrm{M}\right)=1.120 \times 10^{-9} \mathrm{~m}^{2} \mathrm{~s}^{-1}[37]$. 
with increasing calix[4]pyrrole content on the composite film. These results clearly suggest an increase of interactions between the diffusing species and CP; once a decrease of diffusion coefficient is directly related to an increase of time-lag. However, in the case of $\mathrm{NaCl}$ there is no significant alteration in the distribution coefficient from B1 to B4 films; on the other hand, with divalent electrolytes, there is a continuous decrease in the distribution coefficients with increasing CP. There is a selective interaction for higher valent cations, with distribution coefficients decreasing in the order $K\left(\mathrm{CuCl}_{2}\right)>$ $K\left(\mathrm{NiCl}_{2}\right)>K(\mathrm{NaCl})$.

The diffusion coefficients of these electrolytes in the composite films, obtained under steady-state conditions, are dependent on the hydrated radius of the cation, which can be explained by the role of the porous cellulose acetate bulk structure on the transport properties.

\section{Acknowledgement}

Financial support from POCTI/FCT/FEDER (AMB2004/55281, MAT2004/03827, POCI/QUI/ 58291/2004) and MEC/CRUP (Acções Integradas) is gratefully acknowledged.

\section{References}

[1] Mauzerall D. J Am Chem Soc 1960;82:2601.

[2] Allinger NL, Zalkow V. J Org Chem 1960;25:701.

[3] Jang Y-S, Kim H-J, Lee P-H, Lee C-H. Tetrahedron Lett 2000;41:2919.

[4] Nagarajan A, Ka J-W, Lee C-H. Tetrahedron 2001;57:7323.

[5] Allen WE, Gale PA, Brown CT, Lynch V, Sessler JL. J Am Chem Soc 1996;118:12471.

[6] Furusho Y, Aida T. Chem Commun 1997:2205.

[7] Campazzi E, Solati E, Scopelliti R, Floriani C. Inorg Chem 1999;38:6240.

[8] Custelcean R, Delmau LH, Moyer BA, Sessler JL, Cho W-S, Gross D, et al. Angew Chem Int Ed Engl 2005;44:2537.

[9] Calderón V, Scharz G, García F, Tapia MJ, Valente AJM, Burrows HD, et al. J Polym Sci A: Polym Chem 2006;44:6252.

[10] Kimura K, Sakamoto H, Nakamura T. J Nanosci Nanotech 2006;6:1741.
[11] Doelker E. Adv Polym Sci 1993;107:199.

[12] Valente AJM, Polishchuk AYa, Burrows HD, Lobo VMM. Langmuir 2000;16:6475.

[13] Meluch TB, Lloid DR. Polymer 1993;34:1984.

[14] Glasser WG. Macromol Symp 2004;208:371.

[15] Valente AJM, Burrows HD, Lobo VMM. Colloids Surf A: Physicochem Eng Aspects 2006;275:221.

[16] Pud A, Ogurtsov N, Korzhenko A, Shapoval G. Prog Polym Sci 2003;28:1701.

[17] Gardner JS, Walker JO, Lamb JD. J Membrane Sci 2004;229:87.

[18] Vidéki B, Klébert S, Pukánszky B. Eur Polym J 2005;41: 1699.

[19] Calil MR, Gaboardi F, Guedes CGF, Rosa DS. Polym Test 2006;25:597.

[20] Valente AJM, Sobral AJFN, Jiménez A, Patachia S, Oliveira ARCB, Lobo VMM. Eur Polym J 2006;42:2059.

[21] Lobo VMM, Murtinho DB, Gil MH, Garcia FP, Valente AJM. Int J Polym Mater 1996;32:221.

[22] Crank J. The mathematics of diffusion. Great Britain: Oxford University Press; 1975.

[23] Gavara R, Hernandez RJ. J Plast Film Sheet 1993;9:126.

[24] Baes Jr CF, Mesmer RE. The hydrolysis of cations. New York: John Wiley \& Sons; 1976.

[25] Valente AJM, Polishchuk AYa, Burrows HD, Lobo VMM. Eur Polym J 2005;41:275.

[26] (a) Miguel MG. Adv Colloid Interface Sci 2001;89-90:1; (b) Dong DC, Winnik MA. Can J Chem 1984;62:2560.

[27] Polishchuk AYa, Zaikov GE. Multicomponent transport in polymer systems for controlled release. Amsterdam: Gordon Breach Sci.; 1997. p. 14-9.

[28] Sessler JL, Gale PA. In: Kadish KM, Smith KM, Guilard R, editors. The porphyrin handbook. New York: Academic; 2000 [Vol. 6, p. 257-78].

[29] Zaikov GE, Iordanskii AL, Markin VS. Diffusion of electrolytes in polymers, VSP. Utrecht 1988:53.

[30] Nguyen XQ, Sipek M, Hynek V, Nguyen QT. J Appl Polym Sci 1994;54:1817.

[31] Hamilton CJ, Murphy SM, Tighe BJ. Polymer 2000;41:3651.

[32] Nightingale Jr ER. J Phys Chem 1959;63:1381.

[33] Housecroft CE, Sharpe AG. Inorganic chemistry. 2nd ed. Harlow: Pearson Prentice Hall; 2005. p. 587-8.

[34] Valente AJM, Burrows HD, Polishchuk AYa, Domingues CP, Borges OMF, Eusébio MES, et al. Polymer 2005;46: 5918.

[35] Tyrrell HJV, Harris KR. Diffusion in liquids. London: Butterworth; 1984. p. 52.

[36] Lobo VMM. Handbook of electrolyte solutions. Amsterdam: Elsevier; 1990.

[37] Ribeiro ACF, Leaist DG, Lobo VMM, Esteso MA, Valente AJM, Santos CIAV, et al. J Chem Eng Data 2005;50:1986. 